\title{
A desconstrução de Cabo Verde como um brasilim: um cabo-verdiano em terras brasileiras
}

\section{Cláudio Alves Furtado}

- Universidade Federal da Bahia / Salvador,BA, Brasil
cfurtado.unicv@gmail.com

\section{RESUMO}

O artigo procura, a partir de um registro pessoal, refletir sobre as múltiplas e por vezes ambíguas visões que marcam um desconhecimento de africanos do Brasil e dos brasileiros em relação aos africanos, levando, não raras vezes, a construção de narrativas que tendem a essencializar e reificar o Outro. A matriz africana da cultura brasileira e a influência da ancestralidade africana na formação da identidade cultural brasileira, de um lado, e a visão de um Brasil racialmente mestiço e cordial, veiculada tanto em trabalhos acadêmicos quanto nos produtos de exportação como as telenovelas, tende a conformar uma imagem, no mínimo, romântica dos africanos. Tendo como foco de análise, especificamente, a construção imagética do Brasil em Cabo Verde, o texto confronta tal construção com a vivência de uma realidade que teima em não aceitá-la. 


\section{CONTEXTUALIZANDO}

A construção do conhecimento científico é, amiúde, narrada como resultante de um processo de reflexão centrado no pesquisador, enquanto sujeito cognoscente, afastando o cogito de qualquer relação com a emotione. Rigorosamente, tende-se a tornar anódino e asséptico esse processo reflexivo. Um binarismo excludente se impõe, opondo o cognitivo ao não cognitivo, a razão à emoção. Por este motivo, embora fiquem no domínio do não dito, ou, no máximo, nos cadernos de campo íntimos (em regra, esses cadernos não são explorados nem publicáveis), as dimensões subjetivas do processo de pesquisa não são refletidas e, nesse sentido, ficam à margem da escrita dita científica.

Como sugere Mazzocchetti (2015), quando o pesquisador se mostra, fá-lo, em regra, por meio de um jargão que tende a se tornar lugar comum nas narrativas antropológicas, qual seja, a enunciação do lugar de fala do produtor do texto/conhecimento. Na verdade, sustenta esta autora, não basta enunciar o "eu metodológico" (Olivier de Sardan, 2008) que comunica aos leitores o seu meio social, suas origens, seu gênero etc., mas, antes, dever-se-ia ter um posicionamento que teria

comme objectifd'analyser finement l'incidence que ces divers éléments, qui se dégagent de notre personne a eue sur les rencontre, le relations tissées, et, donc sur les données et leur intérpretation, mais aussi sur nos choisx de terrais et d'écriture (Mazzocchetti, 2015: 84).

A reflexão proposta pelo Laboratório de Antropologia Prospectiva (LAAP) da Universidade Católica de Louvain-la-Neuve, Bélgica, e que resultou numa publicação conjunta intitulada Intimité et réflexivité: itinérances d'anthropologues, nos faz pensar'. Com efeito, sustentam os organizadores deste livro que

\section{(...) La pratique de l'ethnographie, telle une expérience vécue de la rencontre} de l'autre, comporte une dimension biographique irréfutable et imprégnant de bout en bout nos travaux. Si le chercheur marque son travail de sa personne, il en est tout autant imprégné en retour et littéralement façonné par les multiples autres croisé en chemin (Defreyne et al., 2015: 5-6).

Acrescentam, ainda, que

(...) ceux/ce que nous, chercheurs en anthropologie, choisissons d' interroger et de comprendre, les lieux où nous décidons de nous rendre, la population auprès de laquelle nous enquêtons, toutes les pistes que nous suivons au préalable et au
1 Durante minha estadia nesta universidade como professor visitante no âmbito da Cátedra Jacques Leclerq pude, como convidado, participar num dos seminários semanais do LAAP. Na ocasião, e a partir da minha experiência de pesquisa, apresentei uma reflexão sobre o tema "reflexividade/intimidade", procurando dialogar com o seminário, que havia retido tal tema como o eixo central das reflexões epistemológicas durante o ano letivo 2013/2014. 
cours d'une enquête, ne sont ni le résultat de rencontres anodines ni le fruit d'un calcul mathématique, mais la conséquence d'un itinéraire lié, sans conteste, à nos histoires personnelles influencées par nos vécus les plus intimes (2015: 6).

As questões levantadas por estes pesquisadores, na esteira do que colocara Laplantine (2012), servem de veio condutor da minha reflexão neste artigo. $O$ exercício de se descortinar a rationale, proposta na publicação do LAAP, serve-me aqui não apenas para a definição do recorte a partir do qual a minha reflexão se dá, como também me faz reavivar e reviver memórias biográficas inscritas na intimidade de quem pensa e busca produzir conhecimento sobre si e sobre outro. Mais ainda, possibilita-me refletir como o estranhamento e a construção da intimidade constituem momentos de um percurso não apenas biográfico, mas também - e para o pesquisador - de produção do conhecimento. Dito de outro modo, e tomando de empréstimo o lema do LAAP, intimidade e reflexividade, ainda que muitas vezes silenciadas, contrapostas, opostas e escondidas, são inseparáveis. No contexto das discussões éticas, para lá das questões estritamente epistemológicas, teóricas ou metodológicas, importa assumir a subjetividade inscrita no processo de produção do conhecimento na plenitude e não apenas como retórica discursiva, ainda que expurgada $d(n)$ o processo de produção dos textos científicos.

Portanto, retomando esta reflexão, minha proposta é pensar a África a partir do Brasil, ou, alargando, a partir do chamado "sul-global". No entanto, o que pretendo é reconstruir o processo que me foi dado no Brasil, de me repensar enquanto sujeito de África e africano, num processo em que, repentinamente, o continente virou conteúdo, ou melhor, os conteúdos viraram continente. Para tanto, lanço mão de um recurso de linguagem, a sinédoque, tomando a parte pelo todo. O cabo-verdiano se transforma em africano, Cabo Verde em África. Quero neste processo compreender como fui obrigado a me rever, num ato de estranhamento, pela negação ou recusa do que eu me imaginara ser $^{2}$, obrigando-me, a um só tempo, a rever e ressignificar o Brasil e seus múltiplos gentílicos.

Fica evidente, pois, que não se trata de uma escolha reflexiva clássica, resultante da construção de um objeto e de uma problemática de pesquisa (Laurent, 2015). Antes, ela surge induzida pelos desafios do presente, ainda que os questionamentos de pensar o continente africano, pensar os africanos e pensar como estes são pensados pelos forasteiros, por mais que se consideram matricial e/ou simbolicamente conectados com aqueles, estivessem presentes no nosso espírito, abafado, é certo, há mais de três décadas.

Esta experiência, por vezes, distópica de viver, apreender e ser apreendido fora do lugar (Motta e Oliveira, 2015), foi vivenciada e relatada por outros estudantes originários do continente africano. O trabalho de Alain Pascal

2 Esse eu é a um só tempo tanto um "eu individual", resultante e inscrito na minha biografia, quanto um "eu coletivo", pois, em muitos contextos, eu não era visto pelos meus interlocutores enquanto uma persona, com nominação, tampouco um "eu mezzo", no caso um cabo-verdiano, mas antes um "macro eu", um africano. 
Kaly (2001) é a este título ilustrativo. Refletindo sobre a condição de "ser preto africano" no Brasil, o autor discorre, a um só tempo de forma narrativo-temporal e reflexiva, sobre a experiência de estudante desde sua chegada em Florianópolis, passando por Salvador e Rio de Janeiro, numa vivência plural de "africano" (não senegalês), preto (mas não preto brasileiro) e proto-intelectual (e não um preto, brasileiro, pobre e das comunidades periféricas das grandes cidades).

As diferenças de abordagem que podem ser encontradas no meu texto em relação ao de Kaly se prendem, por um lado, com o fato dos momentos de nossas experiências serem tanto temporal quanto social e historicamente diversos ${ }^{3}$ e, por outro, pelo fato de eu já dominar a língua portuguesa por ocasião da minha chegada ao Brasil, algo facilitador do processo de diálogo com os interlocutores no país. Acrescem ainda as visões diferenciadas, particularmente aquelas partilhadas em Cabo Verde sobre o Brasil, que se afiguravam muito mais consolidadas na literatura, na música e na ensaística desde meados dos anos 30/40 do século passado, substancialmente diferentes do caso senegalês. Se é verdade, como sustenta Kaly (2001), que o mito da democracia racial também teve forte ressonância nos demais países africanos de onde vieram diversos estudantes intercambistas, no contexto dos países africanos de língua oficial portuguesa ela foi bem mais pronunciada e aconteceu significativamente mais cedo.

Organizei este artigo em três momentos. No primeiro, busco mostrar como o Brasil, no contexto cabo-verdiano, foi erigido em ícone, num referente e num alter-ego de Cabo Verde, aproximando-se do que Sansone denominou de "Uso e abuso do Afro do Brasil na África" (2012). No segundo, a partir de minha biografia e, numa certa medida, bio-etnografia, procuro mostrar como fui descontruído no Brasil, sem uma reconstrução sucessiva, colocando-me como um africano e não cabo-verdiano, ao mesmo tempo em que me impunha uma África fora do lugar (Motta e Oliveira, 2015). No terceiro, busquei refletir sobre como essas formas diversas de autoinscrição (Mbembe, 2001) conduzem a dissonâncias, a des/não conhecimentos recíprocos.

\section{CABO VERDE, MELHOR DIZENDO, SÃo VICENTE É UM BRASILIN}

Os artistas e intelectuais cabo-verdianos, desde os meados dos anos vinte do século passado, têm tido mais que uma aproximação, uma certa veneração pelo Brasil. Podemos, numa démarche histórica mais longa, identificar essa aproximação já no século XIX, quando parte das elites da terra defendeu uma aproximação com o Brasil independente (Andrade, 1987; Pereira, 2015, 2010). O certo é que a partir dos anos trinta do século XX essa aproximação aumenta e uma influên-
3 Na verdade, do ponto de vista temporal, existe uma diferença de uma década. $A$ minha chegada ao Brasil nos anos oitenta acontece ainda durante a fase final do período do governo militar, ainda que na sua agonia. Kaly chega já em plena democratização, após a aprovação da Constituição de 1988. Trata-se de uma diferença significativa, já que na década de oitenta os fluxos e refluxos de pessoas, bens e serviços eram menos volumosos entre o Brasil e os países africanos. Os voos eram relativamente reduzidos assim como o trânsito de estudantes africanos no Brasil, seja ao nível PEC-G (Programa de Estudantes-ConvênioGraduação) seja do PEC-PC (Programa de EstudantesConvênio-Pós-Graduação). 0 tráfico de drogas e o número de africanos atuando como traficantes ou transportadores (mulas) de drogas, era ainda reduzido. Esses contextos diferenciados levam certamente a experiências e vivências plurais e múltiplas. 
cia na música, na literatura e na ensaística se faz sentir de forma acentuada, até a decepção ocorrida nos anos cinquenta, após as publicações que se seguiram ao périplo africano de Gilberto Freyre $(1940,1953,1954,1958,1961)$ patrocinado pelo governo de Lisboa. Tais publicações rapidamente receberam uma reação negativa de intelectuais africanos, primeiramente, com a resposta do intelectual angolano Mario Pinto de Andrade, sob o pseudônimo de Buanga Fele (1955) e, mais tarde, de Baltazar Lopes da Silva (1958). A decepção com Gilberto Freyre não impediu, contudo, que intelectuais cabo-verdianos continuassem a ver o Brasil como seu alter-ego e, eventualmente, como objeto de desejo. Para alguns, Cabo Verde seria um exemplo melhor conseguido da mestiçagem e da crioulidade, num mundo que o mulato criou, para utilizar a expressão cunhada por Gabriel Mariano (1959).

A influência do modernismo brasileiro e, de forma particular, da literatura produzida no nordeste brasileiro por Manuel Bandeira, José Lins do Rego, Erico Verissimo, Jorge Amado e José de Alencar, torna-se bem patente entre os escritores cabo-verdianos a partir dos anos 30. De igual modo, os trabalhos que começaram a emergir nos domínios da história, da antropologia e da sociologia, e que pensavam o Brasil, tais como os de Gilberto Freyre, Sérgio Buarque de Holanda e Caio Prado Junior, bem como Nina Rodrigues, vão ser importantes para que a geração da Claridade se encaminhasse rumo à construção de uma narrativa de nação e da cabo-verdianidade, assente na mestiçagem e na morabeza, o contraponto, pela similitude, da cordialidade brasileira.

A música constitui, também, outro ponto de proximidade. Não me interessa, neste momento, uma análise das aproximações, distanciamentos, similitudes e/ ou determinações entre algumas expressões musicais cabo-verdianas e brasileiras para as quais sugiro a leitura de alguns trabalhos, em minha opinião, ainda não conclusivos sobre a matéria (cf., de entre outros, Alfama, 1910; Dias, 2004; Lima, 2002; Martins, 1988; Ferreira, 1973; Duarte, 1934). Na verdade, procuro nesta reflexão pontuar como as letras das músicas exaltam as proximidades entre as ilhas cabo-verdianas, particularmente a de São Vicente, e o Brasil, e como este se transforma no referente daquela(s).

Comecemos pelas letras musicais. A primeira delas foi escrita por um dos principais compositores cabo-verdianos, B. Leza, de verdadeiro nome Francisco Xavier da Cruz, e a canção se chama "Brasil (Nos Sonho Azul)". Eis a letra:

Bem conchê ess terra morena/Venha conhecer essa terra morena Ondê que cada criola é um serena/Onde cada crioula é uma serena Bem, q'ês nos céu tambêe é de anil/Venha, que o nosso céu também é de anil Éss nos terra piquinina?/ Essa nossa terra pequenina É um padacinho di Brasil/É um pedacinho do Brasil 
Brasil, qui nos tudo tem na peito/ Brasil, que todos nós temos no peito

Brasil, qui no ta sinti na sangue/ Brasil, que nós sentimos no sangue

Brasil, bo é nos irmão/Brasil, és nosso irmão

Sim c'ma nos bo é morena/Assim como nós, és moreno

Brasil no crebu txeu, no crebu txeu, di coração/Brasil, te amamos, te amamos de coração

Vento qui ta bem di sul/Vento que vem do sul

Ta trazê na ses cantos acenos di Brasil/ Traz nos seus cantos acenos do Brasil

Si no ca ta bai, es ca ta dixanu/Se não formos, eles não nos deixam

Brasil bo énos sonho/ Brasil, és nosso sonho

Boé nos sonho azul/És nosso sonho azul

Existe um conjunto de adjetivos e expressões que buscam ressaltar as semeIhanças, nomeadamente, "pedaço do Brasil", "ser irmão", "ter no sangue" "ser moreno", "amar", "estar no peito".

A segunda letra foi imortalizada na voz de Cesária Évora e o seu título é "Carnaval de São Vicente" ${ }^{4}$, do compositor Pedro Rodrigues.

4 Já conhecia São Vicente Na sua alegria, na sua delícia Mas não fazia ideia alguma

J'a'm conchia São Vicente

Na sê ligria na sê sabura

Ma 'm ca pud fazê ideia

S'na carnaval era massab

São Vicente é um brasilin

Chei di ligria chei di cor

Ness três dia di loucura

Ca ten guerra ê carnaval

Ness morabeza sen igual

Nô ten un fistinha mas sossegod

Ca bô exitá bô podê entrá

Coque e bafa ca ta faltá

Hôje é dia di carnaval Se durante o carnaval era ainda mais delicioso

São Vicente é um brasilinho (pequeno Brasil) Cheio de alegria, cheio de cor Nesses três dias de loucura Não há guerra é carnaval Nessa morabeza sem igual

Nós temos uma festinha mais tranquila

Não hesite, podes entrar Bebida e petisco não vão falar Hoje é dia carnaval

São Vicente é um brasilinho (pequeno Brasil) Cheio de alegria, cheio de cor Nesses três dias de loucura Não há guerra é carnaval Nessa morabeza sem igual

São Vicente é um brasilin

Chei di ligria chei di cor

Ness três dia di loucura

Ca ten guerra ê carnaval

Ness morabeza sen igual ( $x 6$ ) 
O Brasil, nas letras das canções, constitui um recurso para retratar São Vicente. A positividade inscrita na realidade brasileira é transposta para o caso cabo-verdiano, legitimando as qualidades de Cabo Verde ou, mais especificamente, de São Vicente. Por isso, repete-se no refrão que São Vicente é um pequeno Brasil. A cordialidade brasileira teria como contraponto a morabeza, a "cordialidade" mindelense. O carnaval brasileiro é tão festivo quanto a "sabura" do carnaval mindelense. A mestiçagem brasileira tem seu referente no caráter "moreno" de São Vicente (Sma bo nos é morena).

Literalmente, se observa uma pasteurização do Brasil, constituindo uma legitimação externa da mestiçagem e da crioulidade. As canções constroem uma narrativa de nação mítica, mas que está igualmente presente em estudos acadêmicos sobre a identidade nacional. Uma análise dos ensaios de cariz socioantropológico publicados no primeiro número da Revista Claridade mostra essa proximidade ao Brasil e às leituras que se faziam da sociedade brasileira. De forma particular, os ensaios de Baltazar Lopes da Silva e Felix Monteiro são extremamente elucidativos. No entanto, seria, sem dúvida, Gabriel Mariano quem mais foi influenciado pelo pensamento brasileiro. O seu texto, "Do funco ao sobrado ou o mundo que o mulato criou", mostra claramente a influência de Gilberto Freyre, mas também fica evidente seu conhecimento de Nina Rodrigues.

De forma sintética, podemos sugerir que os intelectuais cabo-verdianos demonstram, através da música, da literatura e da ensaística, não apenas um forte diálogo com o Brasil, mas também uma forte influência deste no pensar Cabo Verde como nação, num contexto em que se buscava um distanciamento de Lisboa, procurando uma autonomia cultural e identitária.

Nossa pretensão neste primeiro momento reflexivo, ainda que de forma tópica, é mostrar a imagem do Brasil que se projeta para uma parte da sociedade cabo-verdiana, a urbana e com maior acesso à informação, comunicação e escolarização. Esta visão é, mais contemporaneamente, exponenciada pela globalização e pelo aumento dos fluxos e trânsitos entre os dois países. As telenovelas, os filmes, as músicas, o carnaval e o futebol passam a fazer parte do cotidiano das populações cabo-verdianas, neste momento, de forma mais espraiada. Esta visão idílica da sociedade brasileira acaba por conduzir ao que Sansone (2012) denominou de uso e abuso do Brasil em África que, amiúde, é desconstruída pela vivência das desigualdades raciais e sociais no Brasil por parte quem tem na origem social e na cor dois critérios e marcadores identitários importantes.

A idolatria ao Brasil, estranhamente, não se aplicava ao meu caso. O meu conhecimento do Brasil era importante e resultava das leituras obrigatórias no liceu, do acompanhamento de algumas novelas, do futebol e da música. Entretanto, o Brasil nunca fora meu objeto de desejo. 


\section{UM CABO-VERDIANO EM TERRAS BRASILEIRAS: ATO 1}

Casualmente, em 1982, vim parar no Brasil depois de dois anos de problemas burocráticos do Ministério da Educação de Cabo Verde com o meu dossier para prosseguimento de estudos nos Estados Unidos da América. Num voo que se repartiu entre Praia, Dakar, Rio de Janeiro e São Paulo, a expectativa era menos por conhecer o Brasil e mais pela nova experiência de terra longe. Minhas estadias fora das ilhas haviam sido pontuais, excetuando umas longas e interessantes férias juvenis em Dakar, Senegal. De forma particular, o Brasil, diferentemente de muitos de meus conterrâneos, não era a minha primeira ou segunda escolha. Foi a escolha possível naquele momento, já que tivera de ficar dois anos esperando prosseguir meus estudos universitários. No terceiro ano, depois de algumas altercações com os dirigentes do Ministério da Educação, foi-me dada a possibilidade de escolha e, hélas!, escolhi um curso ausente do meu repertório em um país jamais pensado... Mas, decisão tomada, viagem programada e realizada.

Minha chegada, no entanto, foi marcante. A chegada, num grupo de cerca de uma dezena de cabo-verdianos que deveria se distribuir entre São Paulo, Paraná e Minas Gerais, tivemos que testar nossa capacidade de entendimento do português brasileiro. No balcão de check-in para São Paulo, a atendente perguntou: "fumante ou não fumante?". Ninguém compreendeu o "tch/tx" da pronúncia. Primeiro choque de realidade. Felizmente um colega, que tinha chegado um mês antes para cursar marinha mercante no Rio de Janeiro, salvou-nos do sotaque carioca e facilitou os trâmites no Aeroporto Internacional do Galeão. Tomamos o voo para Congonhas numa quinta-feira no fim da tarde. Preciso situar que, para nossa (in)felicidade, chegamos na semana do carnaval. No avião, os jornais populares reportavam centenas de mortos durante a semana. Que susto! Mas haveríamos de sobreviver. É como diz o dito popular cabo-verdiano: a sina de um crioulo.

Chegados a Congonhas e, como tudo estava fechado para o feriado, ninguém que representasse uma instituição pública nos esperava. Felizmente, como há cabo-verdianos até na lua, duas colegas tinham familiares residindo em São Paulo, num dos casos mesmo no bairro contíguo ao aeroporto. O grupo se dividiu entre as duas famílias, da sexta à segunda-feira, quando a normalidade pós-carnaval chegaria 5 .

Na segunda-feira, deslocamo-nos, guiados pelo pastor Fernando Sá Nogueira, nosso anfitrião e protetor, para a USP, nos serviços de cooperação internacional. A simpatia e disponibilidade do senhor Cairbar Macedo foram marcantes, cabendo a ele nos acompanhar para o DOPS (Departamento de Ordem Política e Social) tratar do RNE (Registro Nacional de Estrangeiro). O antigo DOPS marcou-me não apenas pelo caráter sóbrio/sombrio de seu espaço, como por ter sido a primeira vez que passei a ter a noção de meu fenótipo. Com efeito, foi-me
5 A presença cabo-verdiana no Brasil tem dois grandes momentos. O primeiro, nos finais dos anos vinte do século XX, dirigiu-se essencialmente ao Rio de Janeiro, num processo que também conduziu uma parte de cabo-verdianos, sobretudo originários de Santo Antão, São Vicente e São Nicolau, para a Argentina. Nos anos sessenta, uma nova leva, também ela originária dessas ilhas, se desloca inicialmente para as cidades-porto (Rio de Janeiro, Paranaguá e Santos) e, depois, para as cidades da Grande São Paulo (essencialmente Santo André, São Caetano e São Bernardo). Em 1975, uma parte dos cabo-verdianos que se encontrava em Angola, no momento da independência desse país africano, deslocase para o Brasil. Uma parte desses imigrantes passa a residir na Grande São Paulo e outra em Santa Catarina, particularmente no Vale do Itajaí. Vale mencionar, ainda, a presença de missionários, particularmente da Igreja do Nazareno em São Paulo e Campinas. Quando cheguei em São Paulo fiquei com mais dois colegas na residência de um dos pastores cabo-verdianos. $\mathrm{Na}$ vizinhança havia um outro casal de pastores, também cabo-verdianos, sendo que o marido não exercia funções missionárias, uma vez que era funcionário da VASP. 
perguntado e exigido escrever nos formulários qual era a minha cor. Dei-me conta que eu era negro. ${ }^{6}$

Entre idas e vidas na megalópole, com a matrícula feita e nova residência em Pinheiros, as aulas começaram. No primeiro dia de aulas, na verdade semana de calouros, além dos choques habituais e do estranhamento de uns em relação aos outros, questionamentos silenciosos se colocavam. Na Faculdade de Filosofia, Letras e Ciências Humanas, em todos os seus cursos, eram duas as estudantes africanas: uma nigeriana e uma bissau-guineense. Comigo e minha colega cabo-verdiana, fazíamos quatro. Na nossa turma do primeiro ano, bem grande para os meus parâmetros, havia, na minha concepção racial, dois negros. Eu, uma vez que depois da visita ao DOPS sabia que o era, e uma brasileira.

Para mim, duas questões se colocavam. Ou melhor, duas eram as angústias. A primeira questão resultava do estranhamento e do impacto inicial de me sentir, literalmente, um "exótico", num duplo sentido, enquanto negro e enquanto africano (estrangeiro). A segunda questão, articulada à primeira, dizia respeito às perguntas que me eram colocadas: de onde você vem? Onde fica Cabo Verde? É África? Você é africano, com esse sotaque? Parece português. Como você chegou ao Brasil, de ônibus, trem?

Crosso modo, são as mesmas angústias e os mesmos questionamentos colocados e enfrentados por Kaly, embora me pareça que em São Paulo, na USP, a situação pudesse ser-e objetivamente o era-diferente de Florianópolis e da UFSC, Universidade Federal de Santa Catarina. No último caso, pelo relato do senegalês Kaly, tratava-se de um espaço bem monocromático até a chegada de uma leva significativa de estrangeiros que para lá foram fazer curso de língua portuguesa para estrangeiros antes de sua redistribuição para outras universidades e estados da federação.

São Paulo tinha, na sua estrutura demográfica, uma população negra relativamente mais significativa que Santa Catarina. Contava também com o histórico do Movimento Negro, particularmente do Movimento Negro Unificado (MNU). A USP era (é) frequentada por estudantes provenientes de estratos e classes sociais possidentes e que, por essa razão, teriam mais acesso à informação e conhecimento. Na Universidade, quando da minha chegada, já existia um Centro de Estudos Africanos e dois professores africanos faziam parte do quadro docente.

Entre os colegas na Universidade e entre os amigos que foram sendo construídos, a curiosidade, para não dizer o desconhecimento do continente africano era importante. O nível de informação se resumia, em regra, aos casos clássicos (doenças, guerras, e o exótico, não muito longe do que as capitais europeias faziam nas exposições mundiais no começo do século XX), numa folclorização do continente e suas gentes, não apenas a sua essencialização.

Este desconhecimento é fortemente impactante e, por vezes, irritante. Trans-

6 Em Cabo Verde, certamente no âmbito da estratégia da colonização portuguesa de tornar os cabo-verdianos front-office da administração das colônias africanas, proibiram, por volta dos anos trinta e quarenta do século passado, que os censos demográficos trabalhassem a categoria "cor". Questão, aliás, que continua ausente no contexto pósindependência. Escrevi a este respeito em Furtado (2012). 
crevo o depoimento de um togolês, estudante de medicina na Universidade Federal do Rio de Janeiro sobre a sua visão e experiência do Brasil. Trata-se, no essencial, de uma experiência semelhante à relatada pelo senegalês Kaly.

Sou Fleury, estudante de medicina na UFRJ. Cheguei no Brasil em 2011 através de um programa de convênio entre o governo brasileiro e o governo do meu país. Fora do Brasil, temos a visão de um país onde os negros têm acesso a todos os patamares. Chegando aqui, a realidade é completamente outra.

Eu me lembro que quando eu dizia que eu sou do Togo, as pessoas me perguntavam: o que é isso? Outros ainda perguntavam: fica em qual país da Angola? Éo Congo? Eu dizia "não, éo Togo", e tem infelizes que respondiam - "é tudo a mesma coisa". A minha resposta era: então Argentina e Brasil é tudo a mesma coisa. $O$ que mais me surpreendeu foi o dia que eu estava no ponto de ônibus na ilha do fundão e parou um carro na minha frente, e os alunos que estavam dentro do carro, e vestiam camisas da "engenharia UFR]", gritaram para mim: volta para 0 seu país, angolano. Eu fiquei triste mas não por mim, por eles. Fiquei me perguntando como alguém consegue passar para o curso de engenharia e não sabe que ser preto com cara de estrangeiro, não quer dizer ser angolano. Eu fui entender esse pensamento defeituoso um tempo depois: a imagem de que a África é um país, não um continente que tem 54 países. Outra coisa a mencionaré a história da África aqui vendida de pobreza e de miséria (Diponível em: https://fleuryjohnson.wordpress.com/2016/07/21/191/, acesso em 30/07/2016).

Esse tipo recorrente de narrativa entre os africanos no Brasil faz ressaltar duas questões essenciais. De um lado, há o racismo patente na sociedade brasileira, que desmonta o discursivo veiculado no exterior da democracia racial e da cordialidade brasileira. De outro, nota-se o grau de ignorância em relação ao continente africano e sua heterogeneidade. Como já referido, as nacionalidades desaparecem para dar lugar ao "africano". É tudo a mesma coisa. São pretos e é o que basta.

Como aponta Kaly:

Os chamados estudantes africanos que vieram para o Brasil deixaram suas respectivas famílias, os seus bairros e cidades, como Mancagne, Peul, Serere, Diola, Ibo, Banto, Soninké, Bambara, Dioula, Ewe, Touare, Dinka, pegaramo avião como senegaleses, guineenses, camaronenses, gaboneses, marfinenses, argelinos, egípcios, cabo-verdianos, angolanos, moçambicanos, são-tomeenses, $e$ aqui chegaram como "africanos". No país que os acolheu, as diversidades culturais, lingüísticas e étnicas são eliminadas e eles se vêem reduzidos à categoria de monogrupo. Enquanto os estrangeiros europeus, asiáticos e norte-americanos 
são tratados a partir de suas nacionalidades próprias, os da África, não. Somos "africanos", com tudo o que isso carrega de negativo (2001: 112-113).

Como já apontado anteriormente, os africanos perdem suas nacionalidades de origem para serem reduzidos ao continente - enunciações, portanto, acompanhadas por racismo implícito ou explícito. Essas situações, por um lado, e num primeiro momento, levam a um sentimento de frustração e desencantamento com o Brasil vendido lá fora e, por outro, potenciam tensões nas relações dos africanos com os brasileiros.

A relação com a cor constituiu uma outra fonte de espanto. A multiplicidade de cores possíveis nos anos oitenta, manifestas por autoclassificação, era fonte de perplexidade. Não tendo à época um conhecimento aprofundado dos estudos sobre as relações raciais no Brasil, causava-me perplexidade a quantidade de possibilidades de definição fenotípica. Já no meu segundo ano de curso, como estagiário de iniciação científica, tive a possibilidade de participar de uma pesquisa que buscava compreender, no contexto eleitoral, se os eleitores negros teriam ou não uma propensão para votar em candidatos negros. O que para mim era uma evidência se mostrou angustiante. Quando me dirigia a uma pessoa que eu considerava negra para a realização da entrevista era confrontando com uma pluralidade de respostas à questão relativa à autoclassificação da cor/raça. De negro, passando por cafuso, caboclo e cabo verde, as respostas eram múltiplas e me deixavam completamente perdido. Tive que parar a pesquisa e voltar ao meu orientador, o que nos levou à realização de um seminário de pesquisa apenas sobre a taxonomia da cor/raça no Brasil.

Aprendi, ou penso ter aprendido, mas também fiquei com uma outra questão. Na verdade, a multiplicidade de definições de cor disponíveis no Brasil não pareceria colocar-se aos africanos, a partir do momento em que estes eram conhecidos como tal. Na verdade, africanos são negros, se não o forem não são africanos. Vivem ou estão em África.

\section{UM CABO-VERDIANO EM TERRAS BRASILEIRAS: ATO 2}

Cerca de uma década e meia depois de ter deixado São Paulo, retorno ao Brasil, mais especificamente a Salvador da Bahia de Todos os Santos - não apenas a cidade mais negra do Brasil, mas a que possui, dizem, a maior população negra fora do continente africano.

Como sugere Kaly este slogan publicitário e turístico poderia indiciar que os problemas raciais e de inclusão e integração social dos negros estariam resolvidos. Poderia Salvador, portanto, constituir-se num polo de atração para os que gostariam de ver, na prática, a concretização da democracia racial. Seria esta a 
razão porque muitos estudantes, nomeadamente provenientes do continente africano, buscam prosseguir seus estudos universitários no Brasil.

A minha longa vivência do Brasil nos anos oitenta e noventa não me permitiram ter a naïveté de pensar uma Salvador isenta de problemas raciais, malgrado a forte presença das tradições negro-africanas, nomeadamente nos domínios da religiosidade e da cultura popular. A essa presença se podem, ainda, acrescentar os contatos crescentes com o continente, e os estudos africanos e afro-brasileiros se desenvolveram nesta cidade, de forma particular a partir dos anos sessenta do século passado, com a criação do Centro de Estudos Afro-Orientais (CEAO). No entanto, apesar de todos esses desenvolvimentos, uma visão no mínimo essencialista e reducionista das realidades e contextos africanos segue fortemente presente e arraigada.

A agravar a situação, tendo a acreditar que, particularmente para os afro-brasileiros da Bahia, a África e os africanos são vistos e, mais que isso, erigidos em referência ao processo de construção de uma narrativa político-identitária, fundamental para dar organicidade a um projeto a um só tempo identitário e político. $O$ trabalho de Sansone (2002) é relevante a este título. Contudo, queria aqui sugerir que, se é verdade que África, africanos e culturas negras têm sido construídos de formas diversas e por atores diferenciados em contextos geográficos e momentos históricos múltiplos, elas se direcionam, essencialmente, às diásporas.

O que me parece interessante pontuar, a partir da minha experiência, é como as diásporas negras, elas mesmas, não apenas constroem ou manipulam a África, os africanos e as culturas negro-africanas, como esperam, desejam e, em certa medida, sugerem (para não dizer: impõem) aos africanos em contextos migratórios que se definam, se vejam e se reportem à sua própria cultura. Esta África fora do lugar, como bem demonstraram Motta e Oliveira (2015), tensiona as relações e as visões entre os africanos e os brasileiros no Brasil. Uma tensão que, de certa forma, ainda é transversal à sociedade brasileira, tanto entre as comunidades afro-brasileiras e outros grupos sociodemográficos quanto nas universidades e centros de pesquisa.

Vamos por partes. A primeira questão por mim sugerida é que, de forma particular, as comunidades afro-brasileiras projetam uma visão do africano no imigrante africano, esperando - exigindo - que ele performe o que o brasileiro (as comunidades afro-brasileiras) construiu dele (um "dele" imagético e inventado, para tomar de empréstimo a expressão de Mudimbe, 1988). Exemplifico com uma situação que pode parecer folclórica, mas que é elucidativa do que quero sugerir.

Em agosto de 2011, alguns meses após a minha segunda residência no Brasil, desta vez em Salvador, a UFBA hospedou o Congresso Luso-Afro-Brasileiro de Ciências Sociais, que viria a marcar a criação da Associação Internacional de 
Ciências Sociais e Humanas em Língua Portuguesa. No primeiro dia, a organização do Congresso ofereceu aos participantes um cocktail nas instalações da Reitoria. Estava eu numa conversa amena com o colega angolano, José Octávio Van-Dunem, quando se aproxima um então doutorando em Estudos Étnicos e Africanos, também ativo militante negro e das religiões afro-brasileiras para me cumprimentar. Aproveitei a oportunidade para fazer a sua apresentação ao meu colega angolano. De imediato, o novo participante do grupo começa a colocar uma série de questões a Van-Dunem. A primeira delas era sobre o seu nome africano, assumindo que José Octávio, só poderia ser português, e o Van-Dunem, possivelmente holandês. A pergunta ficou sem resposta. Uma segunda questão foi ainda mais enigmática, pois introduzida por uma afirmação hipoteticamente formulada em quimbundo: qual é a sua língua africana? Você sabe o que eu afirmei em quimbundo? Um silêncio imperou! Faltava a terceira questão que, entretanto, não foi enunciada, pois introduzi na pauta da conversa um assunto completamente diverso. A questão em falta seria, certamente, sobre qual era a religião do colega. Digo isto, pois, amiúde, ela me é colocada.

De forma grosseira, pode-se situar as questões feitas ao meu colega angolano em Salvador da Bahia nos seguintes termos: um africano não pode ter um nome completamente europeu e o domínio de línguas africanas, melhor dizendo, de determinadas línguas africanas, constitui signo da africanidade. Não podemos esquecer que, fundamentalmente, pela religião, os naturais de Salvador, particularmente os do candomblé, possuem uma forte ligação com a tradição iorubá e a tradição angola. Neste sentido, conhecimento de rudimentos do iorubá e de línguas autóctones angolanas é encontrado entre os soteropolitanos, podendo indiciar sua ligação com a matriz negro-africana, tornando-se num importante distintivo. No caso, específico do iorubá, o seu conhecimento, de forma especial pelo pessoal de santo, deve-se também ao fato do Centro de Estudos Afro-Orientais (CEAO) oferecer com alguma regularidade um curso de língua e cultura iorubá.

A segunda questão colocada pelo aluno se reporta ao papel das universidades e dos centros de pesquisa na produção e reprodução de uma certa visão e ideia de África. Como já referido, o CEAO foi dos primeiros centros de estudos africanos do Brasil, a par do Centro de Estudos Africanos (CEA/USP) e do Centro de Estudos Afro-Asiáticos (CEAA/IUPERJ), desempenhando um papel importante na promoção dos estudos africanos e afro-brasileiros e também do intercâmbio científico, educacional e cultural do Brasil com alguns países africanos. Contudo, são as culturas afro-brasileiras, particularmente as religiosas, que constituíram e constituem o ponto forte das pesquisas em Salvador e na Bahia, a partir dos estudos sobre escravidão e pós-abolição.

A maior parte, por conseguinte, desses estudos se concentra sobre o Brasil 
e sobre as diásporas afro-brasileiras, não tendo o continente africano qualquer centralidade reflexiva. A África tende a aparecer, em regra, como referencial, matriz, uma matriz muitas vezes idilicamente construída, potenciando, mesmo quando inconscientemente, uma visão homogênea, essencialista e essencializante do continente, seus povos, sociedades e culturas.

Uma diferença de quase duas décadas separa os dois momentos de minha presença nas terras brasileiras. Mudanças importantes aconteceram como, de forma tópica, pude apontar. Na verdade, os anos 2000 transformaram, de forma significativa e positiva, as relações entre o Brasil e o continente africano. No domínio político-diplomático, as relações bilaterais e multilaterais tiveram um aprofundamento relevante. Em termos de investimentos, tanto públicos quanto privados do Brasil em África, um incremento pode ser apontando a par do aumento dos fluxos comerciais. Em termos de intercâmbios acadêmicos e científicos também avanços tiveram lugar. Os programas PEC-C, PEC-PG, específicos da CAPES e do CNPq, a criação da UNILAB, de entre outros, constituem exemplos que merecem destaque.

No domínio da pesquisa, particularmente em ciências humanas e sociais, há um aumento do número de dissertações e teses sobre países, realidades e contextos africanos, embora uma parte importante esteja centrada numa perspectiva comparativa e que, não raro, tende a ver a África a partir do Brasil. Ademais, ainda uma boa parcela desses estudos debruça-se sobre os Países Africanos de Língua Oficial Portuguesa, o que, embora não desejado, pode reforçar uma visão político-ideológica de uma lusofonia inexistente.

No entanto, o grosso dos trabalhos de pesquisa tem estado ainda centrado nos estudos das diásporas africanas, da escravidão, da pós-abolição, das religiões e culturas afro-brasileiras, da estética negra etc., reportando-se à presença da ancestralidade africana no Brasil. Significa, uma vez mais, que o continente africano não apenas é visto a partir de um passado relativamente remoto, como tende a ser apreendido enquanto totalidade, reforçando uma leitura e visão deturpadas e a-históricas das realidades africanas. É o que sustenta Zamparoni quando sugere que

Os africanos e a África que se busca sob esta perspectiva é aquela colocada num freezer, onde a cultura se inscreve num tempo mítico, que se repete, onde não há criação, nem história. Essa imagem mitificada da África tem dado lugar a usos e abusos. Nessa mesma ótica cria-se um tipo "o africano", uma cultura "africana" que supostamente corresponderia ao continente. É dificil crer que essa busca de inspiração, a-histórica, na história, possa efetivamente ajudar de maneira sólida na formação de uma consciência política e social anti-racista (2007: 48). 


\section{PARA NÃO CONCLUIR...}

A presença, cada vez mais importante, de africanos no Brasil tem permitido, muitas vezes de forma emocionalmente desgastante, uma desconstrução da visão difundida do país no exterior. Na verdade há um revisitar do continente (África) e do conteúdo (africanos), a partir do Brasil, por parte dos africanos residentes, especialmente estudantes e pesquisadores, que confronta olhares, temporal e espacialmente diversos e diversificados. Esse esforço desnuda, por vezes de forma dolorosa, o sujeito (africano) que chega às terras brasileiras possuidor de um olhar prévio de "si" e dos "outros". Tal desconstrução e reformatação de identidades individuais e nacionais (Laurent, 2015), num contexto em que elas são confrontadas com uma hétero-identidade continental.

Mais ainda, a presença de africanos em terras brasileiras - e agora assumo, a um só tempo, um "eu" pessoal e um "eu metodológico" (Olivier de Sardan, 2008) -, me/nos transforma, recria e reinventa a partir de continente de origem (África), pela cor a ele associado e por um conjunto de outros estereótipos estabelecidos e estabilizados na sociedade brasileira, tornando-nos africanos e negros e não, por exemplo, cabo-verdiano e negro. Excluem-se, desse modo, quaisquer outras tonalidades fenotípicas como sendo endógenas ao continente. A mesma presença no Brasil reforça a minha nacionalidade e a minha dimensão pan-africana. De forma aparentemente paradoxal, o que me nega, na minha origem, constrói-me num segundo momento, conduzindo à redefinição da(s) minha(s) nacionalidade(s).

Acresce-se, ainda, que esse mesmo processo nos conduz a uma desconstrução do Brasil e dos brasileiros. Com efeito, a discriminação e a estigmatização a que os africanos estão sujeitos reconfiguram sua visão do Brasil. Como afirmou Kaly,

A grande maioria desses estudantes a lega que um dos principais motivos da escolha do Brasil é a suposta democracia racial aqui existente. Mas as constantes humilhações sofridas, em razão dos diferentes tipos de discriminação, estão transformando esses estudantes em atentos (2001:108).

É interessante observar que esse desencantamento - e a desconstrução dele decorrente-em relação ao Brasil multirracial e sua cordialidade tende a se aprofundar na contemporaneidade, de uma forma paradoxal. De um lado, pelo efeito da globalização, que faz aumentar os trânsitos entre africanos de múltiplas nacionalidades e os brasileiros e, por conseguinte, entre as Áfricas e o Brasil (ou seria melhor dizer também Brasis?). De outro lado, tivemos os impulsos político-diplomáticos reforçados de forma significativa com os governos Lula/ Dilma. Com efeito, a intensificação das relações político-diplomáticas, econômi- 
co-comerciais e científico-adicionais permite uma maior capacidade reflexiva e de revisão de saberes iniciais sobre si e sobre o outro, numa relação também de intimidade (Laplantine, 2012) que nos conduz não a pensar em nós, mas na alteridade que se constrói na e da relação. Como sugere, ainda, François Laplantine numa entrevista concedida em 1999 ,

Ce qu'il s'agit de penser, ce n'est pas l'identité, c'est l'altérité. C'est être autre. C'est devenir autre. Je ne mettrais pas ce mot "être". Il ný a pas d'être. Seulement du peut-être. Ce qui n'est pas rien (Laplantine apud Vaugrande Vialaneix, 1999: $s / p)$.

Afinal, não sou quem pensara ser, nem aquilo que me quiseram fazer que eu fosse! Sou apenas um poder ser... O que não é qualquer coisa!!!

Cláudio Alves Furtado é professor da Universidade Federal da Bahia, atuando nos programas de pós-graduação em História e em Estudos Étnicos e Africanos. Desempenhou as funções de Presidente da Associação Internacional de Ciências Sociais e Humanas em Língua Portuguesa (AILPcsh) e membro do Comité Executivo do Conselho de Desenvolvimento da Pesquisa em Ciências Sociais em África (CODESRIA).

\section{REFERÊNCIAS BIBLIOCRÁFICAS}

ALFAMA, José Bernardo

1910 Canções crioulas e músicas populares de Cabo Verde. Lisboa, Imprensa Commercial.

ANDRADE, Mario Pinto

1987 Origens do nacionalismo africano. Lisboa, D. Quixote.

BUANCA FELE / ANDRADE, Mario Pinto de

1955 “Qu'est-ce que 'le tropicalismo'?". Présence Africaine, Paris, v. 9, n. 5: 24-35.

DEFREYNE, Elisabeth et al.

2015 Intimité et réflexivité. Intinérances d'anthropologues. Louvain-la-Neuve, Academia/L’ Harmathan. 
DIAS, Juliana Braz

2004 Mornas e coladeiras de Cabo Verde: versões musicais de uma nação.

Brasília, tese de doutorado, Universidade de Brasília.

DUARTE, Fausto

1934 Da literatura coloniale da morna de Cabo Verde. Lisboa, Sassetti \& C. Editores.

FERREIRA, Manuel

1973 A aventura crioula - ou Cabo Verde uma síntese cultural

e étnica. 2 ed. Lisboa, Plátano Editora.

FURTADO, Cláudio Alves

2012 "Raça, classe e etnia nos estudos em e sobre Cabo Verde. As marcas do silêncio". Afro-Ásia, Salvador, n. 45: 143-171.

FREYRE, Gilberto

1954 Aventura e rotina: sugestões de uma viagem à procura das constantes portuguesas de carácter e aç̧ão. Lisboa, Livros do Brasil.

1958 Integração portuguesa nos trópicos. Col. Estudos de Ciência Política e Social, n. ${ }^{\circ} 6$. Lisboa, Junta de Investigações do Ultramar.

1961 Oluso e o trópico: sugestões em torno dos métodos portugueses de integração de povos autóctones e de culturas diferentes da europeia num complexo novo de civilização: o luso-tropical. Lisboa, Comissão das Comemorações do V Centenário da Morte do Infante D. Henrique.

1940 O mundo que o português criou. Rio de Janeiro, José Olympio.

1953 Um brasileiro em terras portuguesas: introdução a uma possível Iusotropicologia, acompanhada de conferências e discursos proferidos em Portugal e em terras lusitanas e ex-lusitanas da Ásia, África e do Atlântico. Rio de Janeiro, José Olympio.

KALY, Alain Pascal

2001 'O Ser Preto africano no 'paraíso terrestre' brasileiro. Um sociólogo senegalês no Brasil". Lusotopie, 2001: 105-121.

LIMA, António Cermano

2002 Boavista, ilha da morna e do Landú. Praia, ISE.

LAPLANTINE, François

2012 Quand le moi devient autre. Connaître, partager, transformer. Paris, CNRS. 
LAURENT, Pierre-Joseph

2015 "Conséquences personnelles et collectives de l'intimité et de la réflexivité sur la démarche anthropologique". In DEFREYNE, Elisabeth et al. (orgs.). Intimité et réflexivité. Intinérances d'anthropologues. Louvain-la-Neuve, Academia/L'Harmathan.

MARIANO, Gabriel

1959 "Do funco ao sobrado ou o mundo que o mulato criou". Colóquios Cabo Verdianos. Lisboa, Junta de Investigação do Ultramar/

Centro de Estudos Políticos e Sociais, n. 22: 23-49.

MARTINS, Vasco

1988 A música tradicional cabo-verdiana I (a morna). Praia/ Cabo Verde, Instituto Cabo-Verdiano do Livro e do Disco.

MAZZOCCHETTI, Jacinthe

2015 "Basculements sensibles, implications et écritures". In: DEFREYNE, Elisabeth et al. (orgs.). Intimité et réflexivité. Intinérances d'anthropologues. Louvain-la-Neuve, Academia/L’'Harmathan, pp.83-114.

MBEMBE, Achille

2001 "As formas africanas de auto-inscrição". Estudos

Afro-Asiáticos, ano 23, n. 1:171-209.

MOTTA, Antônio e OLIVEIRA, Luiz

2015 "África, africanidades e afrobrasilidades: performances e dramas sociais como experiências museográficas". In FURTADO, Cláudio Alves (org.). Diálogos em trânsito. Brasil, Cabo Verde e CuinéBissau em narrativas cruzadas. Salvador, EDUFBA, pp.47-78.

MUDIMBE, V. I.

1988 The Invention of Africa. Cnosis, Philosophy and the Order of Knowledge. Bloomington e Indianapolis, Indiana University Press.

OLIVIER DE SARDAN, Jean-Pierre

2008 La Rigueur du qualitatif. Les Contraintes empiriques de l'interprétation socio-anthropologique. Louvain-la-Neuve, Academia/Bruylant. 
PEREIRA, Eduardo Camilo

2010 Política e cultura: As revoltas dos Engenhos (1822), de Achada Falcão (1841) e de Ribeirão Manuel (1910). São Paulo, tese de doutorado, Universidade de São Paulo.

2014 "Cabo Verde: elites coloniais e lutas partidárias na primeira metade do séc. XIX (1821-1841)". In FURTADO, Cláudio Alves et

al. (orgs.). As ciências sociais em Cabo Verde: temáticas, abordagens e perspectivas teóricas. Praia, Edições Uni-CV, pp. 280-303.

SANSONE, Lívio

2002 "Da África ao Afro: uso e abuso da África entre os intelectuais e na cultura popular brasileira durante o século XX". Afro-Ásia, 27: 249-269.

2012 "Uso e abuso do Afro do Brasil na África". $36^{\circ}$

Encontro Anual da ANPOCS, Caxambu.

SILVA, Baltazar Lopes

1958 Cabo Verde visto por Gilberto Freyre. Praia, Imprensa Nacional.

VAUGRAND, Henri e VIALANEIX, Nathalie

1999 "Le Métissage, moment improbable d'une connnaissance vibratoire". Entrevista com François Laplantine. X-Alta, n. 2/3: 35-48.

ZAMPARONI, Valdemir D.

2007 "A África e os estudos africanos no Brasil: passado e futuro". Ciência e Cultura (SBPC), v.59 (2). 
The Deconstruction of Cape Verde as a Brasilim:

A Cape Verdean in Brazilian Land

\section{ABSTRACT}

The article seeks, from a personal record, to reflect on the multiple and, sometimes, ambiguous visions that mark an unfamiliarity and a lack of knowledge of Africans from Brazil and Brazilians towards Africans, often leading to construction of narratives that tend to essentialize and reify the "Other". The African matrix of Brazilian culture and the influence of African ancestry on the formation of Brazilian cultural identity, on the one hand, and the vision of a racially mixed and cordial Brazil, conveyed both in academic productions and in export products such as telenovelas tend to build an image, at least, romantic for Africans. Having, specifically, as a focus of analysis the Brazilian image construction in Cabo Verde, the text confronts such construction with the experience of a Brazilian reality that refuses to accept it.

\section{KEYWORDS}

Brazil, Africa, Cabo Verde, Representation, Identity

Recebido em 30 de maio de 2017. Aceito em 6 de novembro de 2017. 